Ирина Беляева

Московский городской педагогический университет

Институт гуманитарных наук

Кафедра русской литературы

Московский государственный университет

имени М.В. Ломоносова

Филологический факультет

Кафедра истории русской литературы

belyaeva-i@mail.ru
УДК 821.161.1.09

https://doi.org/10.18485/slavistika.2020.24.1.14

Оригинални научни рад примљено 31.03.2020. прихваћено за штампу 21.05.2020.

\title{
РУССКАЯ КЛАССИКА И СОВРЕМЕННЫЙ ЧИТАТЕЛЬ
}

В статье речь идет о таких явлениях, как «русская классика» и «русская литература классического периода», о правомерности и критериях их выделения, а также о восприятии русской литературы «от Пушкина до Чехова» современным читателем и о трудностях современной рецепции. К их числу относятся такие проблемы, как слабое напряжение сюжета, влияние стереотипных матриц восприятия, необходимость обращения к реальному комментарию и др.

Ключевые слова: русская литература XIX века, русская литература классического периода, рецепция, Александр Пушкин, Иван Тургенев, Иван Гончаров, Лев Толстой.

The article deals with phenomena such as "Russian classics" and "Russian literature of the classical period", with a question of the legitimacy of the term and the criteria for their selection. We also examine the perception of Russian literature "from Pushkin to Chekhov" by the modern reader and the difficulties of modern reception. These include problems such as weak plot tension, the influence of stereotypical perception matrices, the need to refer to real commentary, etc.

Keywords: Russian literature of the 19th century, Russian literature of the classical period, reception, Alexander Pushkin, Ivan Turgenev, Ivan Goncharov, Lev Tolstoy.

Иерархии в литературе - одна и самых сложных проблем, имеющих прямое практическое значение, поскольку непосредственно связана с вопросом о том, что должно остаться в золотом корпусе словесных текстов той или иной культуры (в нашем случае мы говорим о культуре русской), чтобы он, этот корпус, был сохранен и воспроизводился в читательской практике. Это такая, по большому счету, консервативная задача, без решения которой невозможно сохранение культуры.

Однако мы знаем, что социологи литературы предостерегают от построения незыблемых иерархий, поскольку механизмы появления в культуре т. н. классических (т. е. образцовых) текстов сложен и всегда разнороден (гетерогенен). Определенную лепту в выработку «ценности произведения» вносит, по их справедливому мнению, институализация искусства. «Производителем ценности книги или картины, - пишет Пьер Бурдье, - является не автор, а поле производства, которое, в качестве универсума веры, производит ценность произведения искусства как фетиша, продуцируя веру в творческую силу автора» (Бурдье 2020). «Произведение искусства, - полагает ученый, - существует как символический объект, представляющий ценность, только когда оно распознано и признано, т. е. социально институировано как произведение искусства читате- 
лями или зрителями, обладающими диспозицией и эстетической компетентностью, необходимой для того, чтобы распознать и признать его в этом качестве» (Бурдье 2020). Критики, ученые, «целый ансамбль агентов и институтов», таким образом, «участвуют в производстве ценности произведения посредством производства веры в ценность искусства вообще и веры в отличительную ценность того или иного шедевра» (Бурдье 2020).

При таком подходе становится очевидно, что классические, образцовые для культуры явления - всегда относительны и станут ли они «шедеврами», зависит от многих факторов. Поэтому корпус классических произведений «постоянно изменяется по мере того как изменяется вселенная сосуществующих с ними текстов» (Бурдье 2020). К тому же, как полагают социологи, «по мере того как культурные продукты завоевывают признание, они теряют свою отличительную редкость, и, следовательно, “дешевеют”. Канонизация неизбежно приводит к банализациии». Пьер Бурдье отмечает, что классика зачастую чревата архаикой: «ранее доминантная продукция может быть вытеснена в область “старья” или приобрести статус классики» (Бурдье 2020). Статус «классического» текста в таком случае снижен, а сама классика оказывается синонимична просто литературе старой, с чем, однако, сложно согласиться.

Между тем история литературы как явление живое, хотя и пополняется все время «забытыми именами», расширяется и уточняется - как справедливо отмечал Юрий Лотман, «когда мы говорим об объекте, не прекращающем движения, мы имеем в виду <.. > то, что сам этот период, как и любой период литературы, не является чем-то самим себе равным, а постоянно меняется, поскольку находится в сложных диалогических отношениях с культурным движением последующих эпох. И подобно тому, как нельзя одну реку перейти дважды, нельзя один раз и навсегда изучить историю литературы: река меняется» (Лотман 1994: 393), - она все же имеет свой корпус текстов, которые при любой трансформации (дополнении или удалении) все равно останутся ее основой.

Это связано с тем, что каждая литература, помимо внешних мотивов, имеет свою внутреннюю логику, которая во многом обусловлена генетическими факторами, что особенно актуально для русской литературы, прошедшей в XIX веке, как верно заметил Владимир Линков, «свой путь» (см.: Линков 2012). Русская литература изначально развивалась в «ближневосточном» русле так, что сохраняла отношение к слову как к сакральному знаку, причем помнила об этом всегда, даже, казалось бы, когда она секуляризировалась и адаптировалась к другой литературной модели, связанной с традицией греко-римской античности (см.: Аверинцев 1996).

Наибольшее скрещение эти две линии получили именно в русском XIX веке, что сформировало особый - классический - статус этого периода в русской культуре. Это было время, когда литература для русского читателя была всем и свободно сочетала в себе разные дискурсы - религиозный, философский, социологический, психологический, научный и др. Отрицать наличие такого периода в истории русской литературы было бы несправедливо, и, по верному наблюдению Юрия Лотмана, читатель всегда интуитивно его выделяет. «Нельзя не заметить, - отмечал исследователь в одной из своих последних работ, - что русская литература между Пушкиным и Чеховым представляет собой бесспор- 
ное единство», «бесспорно единое историческое явление», и «именно так она воспринимается, например, нерусским, европейским читателем» (Лотман 1994: 380). Юрий Лотман исходит в своей периодизации русской литературы не только из всегда относительной, как полагают социологи литературы, аксиологии, - хотя он делает на этом акцент тоже, и делает его справедливо, - но ученый сосредоточивает свое внимание на историзме, говорит о классическом периоде как об историческом этапе. Это подразумевает, что на определенном хронологическом отрезке русской литературой были продемонстрированы особые качества, позволившие ей сказать свое слово в культуре мировой - причем на равных и «органически» самостоятельно. «...Культура и литература между Пушкиным и Чеховым, - утверждает Юрий Лотман, - является не только художественной вершиной, не только периодом, когда русская литература становится мировой литературой, но и явлением органического единства» (Лотман 1994: 380). Здесь исследователь едва ли не прибегает к языку описания Аполлона Григорьева, в плане смыслового наполнения слова «органический». Ученый признает, что, несмотря на «смену эволюционных моментов» и на «полемику, раздирающую современников русской культуры XIX в.», в ней существует «то единое, что позволяет нам выделить этот период как совершенно уникальное и целостное явление в истории как русской, так и мировой культуры» (Лотман 1994: 380. Выделено нами. - И. Б.).

Русская литература классического периода, конечно, не замыкается на узком круге книг, она включает в себя все тексты, классические и неклассические, которые относятся к этому хронологическому отрезку. Но определять своеобразие этого периода будут отдельные, наиболее значимые сочинения, которые все же, вопреки пониманию Пьера Бурдье, не могут устареть (перейти в разряд «старья») и актуальны вне времени, во многом в силу своей «органичности» для породившей ее культуры. И потому культура более позднего времени без этих текстов просто не может обойтись - иначе она перестанет быть собой. Институциям все же сложно поддерживать актуальность давно созданного текста, если бы в нем самом не содержалось предрасположенности к тому, чтобы не терять эту актуальность. Однако можно и согласиться с французским ученым в том, что поддержание подобного статуса русской классики зависит от культурной традиции, научной, читательской и школьной практик. И в этом смысле сохранение классики как феномена русской культуры должно подпитываться теми, кто будет ее интерпретировать, учить понимать, ведь филология и есть «служба понимания» (Аверинцев 1969: 101). А если это так, то здесь перед нами встает вопрос и о современном читателе и о том, какие он испытывает трудности в деле понимания классики.

Отношение к русской литературе XIX века - напомним, что, согласно Юрию Лотману, это и есть классический период русской литературы, - в современной России неоднозначное. Есть читатели, для которых она представляет непреходящую ценность, причем зачастую аксиология классических текстов находится в поле стереотипного восприятия. Но есть немало читателей, для которых интереснее современный литературный процесс, поскольку именно он - явление живое и настоящее, тогда как классическая литература - явление прошлого, постепенно и стремительно становящееся позапрошлым (тут очевидно реа- 
лизовывается логика Пьера Бурдье). В этой связи одной из насущнейших задач филологии - получается, что одной из институциональных задач, - является определение затрудняющих восприятие аспектов и выявление новых стратегий прочтения, которые бы актуализировали смыслы «старых» и, казалось бы, привычных литературных сочинений.

В контексте обозначенной проблемы особую сложность представляют не столько традиционно «непростые» Федор Достоевский и Лев Толстой, сколько, казалось бы, более «понятные» Александр Пушкин, Иван Гончаров или Иван Тургенев - «понятные» и «простые», потому что они вроде бы не отягощают своих читателей философской дискурсивностью и постановкой конечных вопросов (по крайней мере многим так кажется). Интерес к первым все же не ослабевает, ибо он в немалой степени подпитывается мировым признанием, тогда как последние либо не завоевывали его, либо, к сожалению, к настоящему моменту утратили. Так обстоят дела, например, с Иваном Тургеневым, который первым из русских писателей вошел в западноевропейскую литературу, был признан там в профессиональной среде, едва ли не первым стал оказывать ощутимое влияние на европейских и американских литераторов, но сейчас уступил свое ведущее когда-то место Федору Достоевскому, Льву Толстому и Антону Чехову.

Основные трудности в деле понимания и в практике изучения русской классики на настоящем этапе можно, конечно, объяснить кризисом литературоцентризма, который затронул и Россию. Это, нужно сказать, особенно болезненно для нее, поскольку русская культура всегда была литературоцентричной, она так преимущественно формировалась, в отличие от других европейских культур, чем во многом обязана своим «ближневосточным» истокам. Но дело не только в этом. Есть и частные усложняющие восприятие факторы.

Отдельный труд в чтении текстов XIX века составляет необходимость обращаться к реальному комментарию, поскольку жизнь стремительно меняется. Так в «нанковом кафтане», часто встречающимся, например, в текстах Ивана Тургенева или Льва Толстого, современный читатель с трудом увидит сделанную из грубого хлопка вещь, не так просто ему разобраться и в «верстах» и «саженях», которыми измерялись в России в позапрошлом веке расстояния. Подобных примеров можно было бы привести очень много. Детали повседневной жизни, географические названия, исторические события - все это, и не только это, требует сейчас пояснения, а значит и дополнительной работы от читателя. Но с подобными вещами еще можно было бы смириться. В конце концов, школьнику и студенту в какой-то момент может оказаться увлекательным узнавать о том, как в онегинскую эпоху были устроены дороги, балы, дуэли и обеды.

Гораздо сложнее обойтись читателю сейчас без острой сюжетики. Кстати, те сочинения, где она появляется, в том числе в виде детективного элемента, например, у Федора Достоевского, значительно быстрее доходят до современного адресата. А вот событийность пушкинского «Евгения Онегина» молодому читателю может оказаться сомнительной, поскольку происшествий там действительно мало, роман можно пересказать в нескольких предложениях. Сюжет внешне прост и не насыщен событиями. И читателю нужно приложить немало 
усилий, чтобы разглядеть главное, увидеть, что называется, между строк, подобно тому, как это делал Онегин в 8 главе романа: «Он меж печатными строками / Читал духовными глазами / Другие строки» (Пушкин 1978: 158).

Поэтика Пушкина подразумевает значимое умолчание, которое становится подчас смыслообразующим - в том же «Евгении Онегине», - когда читатель с трудом вдруг осознает, что главная встреча в романе, встреча Онегина и Татьяны, почему-то никак не описана, а замещена знаменитыми отточиями. Ему довольно трудно понять, как можно было «пропустить» главное событие, вообще ничего не сказать о нем в и без того «бессобытийном» романе, но художественный эффект от этого пропуска оказывается колоссальный. Подобных моментов в романе немало - что стоит «пропущенное» путешествие Онегина, которое поэт планировал сделать 8 главой, но оно стало приложением к роману, а на самом деле его важнейшей частью. Это невысказанное, неописанное событие, нюансы встречи Онегина и Татьяны, самой главной и важной для героев, которое изменит все их существо к лучшему, читатель «дочитывает», или «дописывает» сам - и это очень сложно. Он вынужден неоднократно возвращаться к реакции Онегина - к его нелепому вопросу о том, «которая Татьяна», что он задает Ленскому на обратной дороге, будто он не знал, кто из трех Лариных, «старушки»-матери и двух барышень, есть кто. Читатель задумывается и соединяет начало и конец - первую и последнюю встречу Онегина и Татьяны и выстраивает невольно тот, не нашедший событийного выражения «возможный сюжет» романа, о котором писал Сергей Бочаров (Бочаров 1999: 17-45). Как только читатель задумывается о причинах и об эффекте подобной «бессобытийности» (а «бессобытийность» лишь иллюзия, на самом деле события происходят грандиозные), то он вынужден постоянно разгадывать этот пушкинский quest. Но современный читатель не привык, или отвык от подобной деликатной подачи материала и постановки проблемы, поэтому ему нужно совершить определенную работу и над собой.

Стоит сказать, что пушкинское умение не сказать напрямую главное очень ценили его немногие почитатели в Европе, во Франции, например. Иван Тургенев вспоминал, что Проспера Мериме восхищало в Александре Пушкине то, что в некоторых его текстах - речь шла об «Анчаре» - отсутствовали «всякие толкования и моральные выводы». «Всякий новейший поэт, - вспоминал Иван Тургенев слова Проспера Мериме, - не удержался бы тут от комментариев» (Тургенев 1986: 345).

Немало интересу к классическим текстам препятствуют стереотипы восприятия, или напластования разных матриц восприятия, которые сложились в разные временные периоды. Порой литературно-критические оценки становятся догматической схемой интерпретации того или иного текста. Сами по себе эти оценки могут быть справедливыми в своей системе координат, но когда они и только они доминируют, например, в школьной практике, то это способствует тому, что пути, ведущие к другим смысловым структурам текста, закрываются. Так обстоит дело - или обстояло, поскольку есть надежда, что ситуация потихоньку меняется, - с Иваном Гончаровым и одним из самых известных в России его романов «Обломов». Трактовка Николая Добролюбова, высказанная критиком давно, в год первой публикации романа (1859), и благожелательно воспри- 
нятая самим автором, в XX веке в России в силу сложившихся обстоятельств стала доминирующей. Илья Ильич Обломов оценивался преимущественно как неприспособленный к жизни барин, не умеющий сам надевать чулки, и это осуждение и порицание барского неделания распространялось и на все дворянское сословие, и на Илью Ильича как на худшего его представителя. Еще во времена Ивана Гончарова подобная оценка прижилась, так что Обломов был записан каким-то неведомым образом в «лишние люди»-хотя справедливости ради стоит сказать, Николай Добролюбов не пользовался этой метафорой. Все это в какой-то момент заставило возмутиться самого Ивана Гончарова, когда он «прочитал в газетах», что один немецкий критик написал «в каком-то немецком журнале (Rundschau) (?) отзыв об Обломове и, между прочим, относит его к лишним людям: Вот и не понял!» Писатель утверждал, что «лишних людей» много - «полна вся русская толпа», а вот таких, как Обломов - «не-лишних» «меньше» (Гончаров 1980: 476). Федор Достоевский увидел, возможно, это обломовское «касание мирам иным» (Осипов 2012: 182), когда заметил: «а мой идиот ведь тоже Обломов», - но общее недоверие к герою сказалось и тут. «Только мой идиот лучше гончаровского, - продолжил он. - Гончаровский идиот - мелкий, в нем много мещанства, а мой идиот - благороден, возвышен» (Ф.М. Достоевский в воспоминаниях... 1892: 308). Роман Ивана Гончарова сложен, и едва ли даже сейчас найдены к нему нужные «ключи», о чем сожалел еще сам писатель в статье «Лучше поздно, чем никогда».

Не менее драматически складывается ситуация с Иваном Тургеневым. Современный читатель в России знает о нем большей частью как о писателе, чьи сочинения изучались в курсе школьной программы - это роман «Oтцы $u$ дети», «Записки охотника». Бывают и счастливые исключения, когда Тургенева читают много и с интересом - такие случаи тоже имеют место быть. Но в целом мало кто сейчас, если не считать очень узких специалистов, обращается к Тургеневу. Многим этот «классик» кажется непонятным и даже скучным, потому что не отвечает современным ритмам и темпам. И нередко у современного читателя возникает вопрос: а настолько ли Тургенев велик, как это принято считать, чтобы его книги можно было перечитывать?

Нужно признать, что в начале XX столетия подобные вопросы тоже возникали. Как относиться к Тургеневу? Не ушел ли он в прошлое вместе со своим временем? Юлий Айхенвальд в «Силуэтах русских писателей» высказал мысль, которая и сейчас многим представляется справедливой: критик назвал Тургенева «туристом жизни», который «все посещает, всюду заглядывает, нигде подолгу не останавливается», и в целом лишен «пафоса и подлинной серьезности», потому что из действительности «вынул <...> трагическую сердцевину» (Айхенвальд 1908: 138). Ивану Тургеневу, по мысли Юлия Айхенвальда, неведомы вопросы жизни и смерти, и даже любовь у него - вымышленная. Потому тургеневская проза остается для читавших и даже почитавших его в свое время знатоков лишь «сладостной страницей» (Айхенвальд 1908: 147), которую стоит оставить в прошлом - ее нельзя брать в настоящее. Сказано это было давно, но и сейчас хорошо описывает современную матрицу восприятия писателя.

Другое положение из оценки Тургенева Юлием Айхенвальдом тоже близко современному читателю: критик считал, что «Тургенев не глубок» и что «во 
многих отношениях его творчество - общее место» (Айхенвальд 1908: 138). Особенно это проявляется в его сравнении с Федором Достоевским и Львом Толстым. Однако к чтению книг Тургенева нельзя подходить с теми же мерками, которые применимы к вышеназванным авторам, потому что смыслы тургеневских текстов рождаются исключительно в сфере художественности и во многом подчинены той же поэтике умолчания, которую можно наблюдать и у Александра Пушкина, о чем шла речь выше. Примером тому могут служить знаменитые тургеневские романные эпилоги, в которых иногда явно, а иногда скрыто и даже с трудом узнаваемо присутствует между тем значимая для смысла целого романа цитация или аллюзия, которая предполагает читательскую стратегию «перепрочтения» всего текста ввиду этой важной и заключительной фразы. Читатель романов Ивана Тургенева должен обладать способностью считывать эти аллюзии и цитации и переживать на себе их неотразимое воздействие. Тургенев практически везде оставляет читателю «шифры» и «ключи» к своему тексту. Так, в финале романе «Отщьы и дети» он соединяет пушкинские строки о «равнодушной природе» со словами из заупокойного песнопения, а в «Дворянском гнезде» - сложно сочетает цитаты из Пятой и Третьей песен первой кантики «Божественной Комедии» Данте Алигьери (См.: Беляева 2018). Без понимания, зачем он это делает (едва ли подобные моменты можно объяснить бессознательными процессами), не разобраться в тургеневских романах, а ведь они кажутся очевидными. Это лишь немногие примеры, доказывающие, что Тургенев и глубок, и, к сожалению, слишком сложен, чтобы массово привлечь к себе читателя. Как «классик» он остается писателем «элитарным» и «для немногих». Но позиций своих не теряет и, хочется надеяться, не утратит в будущем.

Являясь в свое время для читателя одновременно и объектом эстетическим, и уходящим в сферы задач религии, философии, социологии, психологии, русская литература XIX века создала тексты, в которых представлена совершенно уникальная человековедческая практика. Ею питается литература и культура и по настоящее время, без влияния русских книг трудно сейчас представить себе открытия Зигмунда Фрейда и Карла Юнга. Русские писатели глубоко проникли в духовно-психологическое ядро личности, что не может не привлекать к себе читателя, в какое бы время он ни жил. Художественный антропологизм Михаила Лермонтова, Александра Герцена, Ивана Гончарова, Ивана Тургенева, Федора Достоевского, Льва Толстого, Николая Лескова - тоже отличительная черта классического периода. Можно вспомнить глубокое замечание Михаила Лермонтова о том, что «история души человеческой, хотя бы самой мелкой души, едва ли не любопытнее и не полезнее истории целого народа» (Лермонтов 1981: 225), или утверждение молодого Федора Достоевского, только вступающего на литературное поприще, что «человек есть тайна» и что разгадывать ее придется всю жизнь (Достоевский 1996: 21), или суждения Александра Герцена о том, что «биографии» отдельных людей «раскрывают всю роскошь мироздания» (Герцен 1955: 87), или Льва Толстого, уже в пору работы над первыми своими сочинениями прозревающего закон «текучести» человека, который он сформулирует в своих дневниках гораздо позже. В его «Дневнике» за 1898 год (запись от 3 февраля) есть такие строки: «Одно из самых обычных заблужде- 
ний состоит в том, чтобы считать людей добрыми, злыми, глупыми, умными. Человек течет, и в нем есть все возможности: был глуп, стал умен, был зол, стал добр, и наоборот. В этом величие человека. И от этого нельзя судить человека. Какого? Ты осудил, а он уже другой. Нельзя и сказать: не люблю. Ты сказал, а оно другое» (Толстой 1953: 179). Или днями позже (запись от 19 марта) Лев Толстой пишет: «Одно из величайших заблуждений при суждениях о человеке в том, что мы называем, определяем человека умным, глупым, добрым, злым, сильным, слабы[м], а человек есть всё: все возможности, есть текучее вещество, есть...», и далее в дневнике следовала графическая картинка, изображающая человека, которая напоминала реку с неровными берегами (Толстой 1953: 185). Не случайно в романе «Воскресение» писатель уже сравнит человека с рекой напрямую: «...Люди как реки: вода во всех одинаковая и везде одна и та же, но каждая река бывает то узкая, то быстрая, то широкая, то тихая, то чистая, то холодная, то мутная, то теплая. Так и люди. Каждый человек носит в себе зачатки всех свойств людских и иногда проявляет одни, иногда другие и бывает часто совсем не похож на себя, оставаясь все между тем одним и самим собою» (Толстой 1936: 194). Все персонажи Льва Толстого именно таковы - они не укладываются ни в какие классификационные схемы.

Созвучен со Львом Толстым и Иван Тургенев, которому удалось фиксировать антропологическую загадку в статьях о переводе «Фауста» (1845) и о «Гамлете и Дон Кихоте» (1860) и воплотить в своих сочинениях 1850-1860-х годов. Он констатировал, что в человеке чередуются, сменяются качества крайние - «гамлетовские» и «донкихотские», при этом сама же человеческая «натура» остается единой (другое дело, что он не говорит, что определяет эту натуру вне обозначенных «крайних граней», что, условно говоря, находится посредине человеческой целостности, что внутри, чем она наполнена). Оттого каждый человек не есть в полном смысле Гамлет или Дон Кихот - такие чистые типы есть только у Шекспира и Сервантеса - обычный человек может только «сбиваться», в зависимости от ситуации или своего внутреннего настроя, либо на Гамлета, либо на Дон Кихота. Та двойственность, которая фактически обнаруживается в этом более чем амбивалентном, согласно Тургеневу, соединении разнополярных качеств, позволяет говорить, что человек, по его мысли, не может быть сведен к типу Гамлета или Дон Кихота. Его антропологическая природа всегда вмещает в себя и то, и другое, потому что человек меняется и никогда не бывает одним и тем же. Иван Тургенев подчеркивал, что, говоря о современных Гамлетах и Дон Кихотах, он и не думал «утверждать невозможность изменений и противоречий в человеческой природе...» (Тургенев 1980: 331). Гамлетовскодонкихотскую «текучесть» человека неизменно ощущает в персонажах Ивана Тургенева и современный читатель, призванный каждый раз, обращаясь к его сочинениям, решать для себя вопрос о сущности человеческой личности. Русская литература классического периода представляет собой в принципе благодатную почву для этого.

Итак, русская литература классического периода - явление живое, а потому открытое, заново пополняемое воспринимающей ее эпохой, но при всей относительности ценностных координат и литературных репутаций в ней есть и всегда будет корпус текстов, без которых современная культура не сможет су- 
ществовать. Эти тексты могут оказываться все более сложными для понимания новым читателем, но тут должны вступать на свое поле филологи и осуществлять важнейшие институциональные задачи культуры - служить общему делу понимания.

\section{Использованная литература}

Аверинцев, Сергей С. «Греческая “литература” и ближневосточная “словесность”. Противостояние и встреча двух творческих принципов». [В:] С.С. Аверинцев. Риторика и истоки европейской литературной традиции. Москва: Языки русской культуры, 1996, 13-75.

[Averintšsev, Sergeĭ S. "Grecheskaiā "literatura" i blizhnevostochnaiā "slovesnost"”. Protivostoiânie i vstrecha dvukh tvorcheskikh printsipov». [V:] S.S. Averintsev. Ritorika i istoki evropeřskoĭ literaturnoĭ traditșii. Moskva: IAzzyki russkoĭ kul'tury, 1996, 13-75]

Аверинцев, Сергей С. «Похвальное слово филологии». Юность 1. 1969: 99-101.

[Averintšev, Sergeĭ S. «Pokhval'noe slovo filologii». IUnost' 1. 1969: 99-101]

Айхенвальд, Юлий И. Силуэты русских писателей. Вып. 2. Москва: Научное слово, 1908.

[Aĭkhenval'd, IOliı̌ I. Siluetty russkikh pisatelě̌. Vyp. 2. Moskva: Nauchnoe slovo, 1908]

Беляева, Ирина А. «“Помни мои последние три слова”: к вопросу о структуре финалов в романах Тургенева». Филологический класс 3, том 53, 2018: 25-32.

[Beliâeva, Irina A. "“Pomni moi poslednie tri slova": k voprosu o strukture finalov v romanakh Turgeneva». Filologicheskiǔ klass 3, tom 53, 2018: 25-32]

Бочаров, Сергей Г. Сюжеты русской литературы. Москва: Языки русской культуры, 1999.

[Bocharov, Sergeř G. Siūzhety russkoĭ literatury. Moskva: IAłzyki russkoî kul'tury, 1999] Бурдье, Пьер. «Поле литературы» [Электронный ресурс: Социологическое пространство Пьера Бурдьё] <http://bourdieu.name/content/burde-pole-literatury> 30.04.2020

[Burd'e, P'er. «Pole literatury» [Ėlektronnyı̆ resurs: Sotsiologicheskoe prostranstvo P'era Burd'ë] <http://bourdieu.name/content/burde-pole-literatury $>30.04 .2020]$

Линков, Владимир Я. «Свой путь русского реализма». Русская словесность 5, 2012: 9-21.

[Linkov, Vladimir IA. «Svoĭ put' russkogo realizma». Russkaiâ slovesnost' 5, 2012: 9-21]

Лотман, Юрий М. «О русской литературе классического периода. Вводные замечания». [В:] Ю.М. Лотман. Лекции по структуральной поэтике. Избранные статьи и выступления 1992-1993 гг. Москва: Гнозис, 1994, 380-393.

[Lotman, IUriǐ M. «O russkoĭ literature klassicheskogo perioda. Vvodnye zamechaniiā». [V:] IO.M. Lotman. Lektşii po struktural'noŭ poètike. Izbrannye stat'i i vystupleniiā 1992-1993 gg. Moskva: Gnozis, 1994, 380-393]

Осипов, Николай Е. «Обломов и обломовщина. (Заметки психиатра)». [В:] Мастер русского романа И.А. Гончаров в литературной критике русского зарубежья. Москва: Центр книги Рудомино, 2012, 159-231.

[Osipov, Nikolaĭ E. «Oblomov i oblomovshchina. (Zametki psikhiatra)». [V:] Master russkogo romana I.A. Goncharov v literaturnoĭ kritike russkogo zarubezh'iâ. Moskva: TSentr knigi Rudomino, 2012, 159-231] 


\section{Источники}

Герцен, Александр И. Собрание сочинений: В 30 томах. Том. 4. Москва: Наука, 1955.

[Gertsen, Aleksandr I. Sobranie sochineniǐ: V 30 tomakh. Tom. 4. Moskva: Nauka, 1955]

Гончаров, Иван А. Собрание сочинений: В 8 томах. Том 8. Москва: Художественная литература, 1980.

[Goncharov, Ivan A. Sobranie sochineniŭ: V 8 tomakh. Tom 8. Moskva: Xudozhestvennaiā literatura, 1980]

Достоевский, Федор М. Собрание сочинений: В 15 томах. Том. 15. Санкт-Петербург: Наука, 1996.

[Dostoevski1̌, Fedor M. Sobranie sochineniǔ: V 15 tomakh. Tom. 15. Sankt-Peterburg: Nauka, 1996]

«Ф.М. Достоевский в воспоминаниях типографского наборщика в 1872-1881 годах». Русская старина 5, 1892, 293-336.

[«F.M. Dostoevskiǔ v vospominaniiakh tipografskogo naborshchika v 1872-1881 godakh». Russkaiā starina 5, 1892, 293-336]

Лермонтов, Михаил Ю. Собрание сочинений: В 4 томах. Том 4. Ленинград: Наука, 1981.

[Lermontov, Mikhail IU. Sobranie sochineniǐ: V 4 tomakh. Tom 4. Leningrad: Nauka, 1981]

Пушкин, Александр С. Полное собрание сочинений: В 10 томах. Том 5. Ленинград: Наука. 1978.

[Pushkin, Aleksandr S. Polnoe sobranie sochineniǔ: V 10 tomakh. Tom 5. Leningrad: Nauka. 1978]

Толстой, Лев Н. Полное собрание сочинений: В 90 томах. Том. 32. Воскресение. Москва: ГИХЛ, 1936.

[Tolstol̆, Lev N. Polnoe sobranie sochineni1̌: V 90 tomakh. Tom. 32. Voskresenie. Moskva: GIXL, 1936]

Толстой, Лев Н. Полное собрание сочинений: В 90 томах. Том. 53. Дневники и записные книжки 1895-1899. Москва: ГИХЛ, 1953.

[Tolstor̆, Lev N. Polnoe sobranie sochineniĭ: V 90 tomakh. Tom. 53. Dnevniki i zapisnye knizhki 1895-1899. Moskva: GIXL, 1953]

Тургенев, Иван С. Полное собрание сочинений и писем: В 30 томах. Сочинения: В 12 томах. Том 5. Москва: Наука, 1980.

[Turgenev, Ivan S. Polnoe sobranie sochineniǐ i pisem: V 30 tomakh. Sochineniiāa: V 12 tomakh. Tom 5. Moskva: Nauka, 1980]

Тургенев, Иван С. Полное собрание сочинений и писем: В 30 томах. Сочинения: В 12 томах. Том 12. Москва: Наука, 1986.

[Turgenev, Ivan S. Polnoe sobranie sochineniǐ i pisem: V 30 tomakh. Sochineniiâ: V 12 tomakh. Tom 12. Moskva: Nauka, 1986] 


\section{Ирина Бељајева}

\section{РУСКА КЛАСИКА И САВРЕМЕНИ ЧИТАЛАЦ}

\section{Резиме}

Руска књижевност из класичног периода или књижевност „од Пушкина до Чехова» (Јуриј Лотман) - није у толикој мери „симболички објекат“, на известан начин створен кроз институције, одговорне за њену симболизацију, као што то сматра Пјер Бурдје, колико „органска» културна појава, која поседује своју унутрашњу вредност и у свим трансформацијама не губи на свом значају и „класичности“ (узорности). У руској књижевности из класичног периода, уз све могуће измене њеног састава (што је такође неизбежно и посве природно), увек ће остајати својеврсни златни корпус текстова, без кога култура датог доба не може да постоји. То је у многоме условљено специфичном генезом руске књижености, која је управо у XIX веку, тј. у периоду „од Пушкина до Чехова“ формирала свој национални модел. Тај модел се заснива на јединственој вези двеју традиција односа према речи - „блискоисточној“ и „грчкој“ (античкој). Посебно, истовремено експлозивно и органско једињење ових линија формирало је класични период у руској књижевности, који ће увек бити у фокусу пажње културе. Међутим, класични текстови истовремено представљају одређену потешкоћу за савремену рецептивну свест, пошто захтевају не само урањање у свакодневицу, историју, познавање реалија, већ нуде читаоцу другачији темпо, ритмове, који одликују фабуларност, поетику и проблематику ових књига. У чланку се откривају поједине потешкоће при разумевању познатих класичних текстова. Реч је о томе како да савремени читалац изађе на крај са „оскудицом збивања“ у роману Алекснадра Пушкина „Евгеније Оњегин“, како да дешифрује завршетке романа Ивана Тургењева, како да разуме „флуидност“ јунака руске књижевности, укључујући ту и ликове Лава Толстоја, као и зашто Обломова не треба доживљавати као „сувишног човека“.

Кључне речи: руска књижевност XIX века, руска књижевност из класичног периода, рецепција, Александар Пушкин, Иван Тургењев, Иван Гончаров, Лав Толстој. 